\title{
Breast Milk Jaundice: Effect of $3 \alpha 20 \beta$-pregnanediol on Bilirubin Conjugation by Human Liver
}

\author{
B. P. F. ADLARD and G. H. LATHE \\ From the Department of Chemical Pathology, University of Leeds
}

\begin{abstract}
Adlard, B. P. F., and Lathe, G. H. (1970). Archives of Disease in Childhood, 45, 186. Breast milk jaundice: effect of $3 \alpha, 20 \beta$-pregnanediol on bilirubin conjugation by human liver. The effect of $3 \alpha, 20 \beta$-pregnanediol and other steroids on bilirubin conjugation was examined using liver tissue from human and four other species. Neither $3 \alpha, 20 \beta$-pregnanediol nor $3 \alpha, 20 \alpha$-pregnanediol inhibited conjugation by human liver slices or by solubilized human liver microsomes. $3 \alpha, 20 \beta-$ pregnanediol is unlikely to be the inhibitor causing breast milk jaundice.

Oestriol inhibited conjugation by human liver slices. A comparison of species indicated that the response of the human liver slice system to steroids resembles that of the rabbit and guinea-pig rather than the rat or mouse.
\end{abstract}

Newman and Gross (1963) reported the associ2tion of prolonged newborn jaundice with breast feeding. In those infants who were transferred to cow's milk a rapid fall in plasma bilirubin occurred. Arias et al. (1964) confirmed the clinical observations, and showed that the mother's milk inhibited bilirubin conjugation by liver slices and homogenates. They isolated $3 a, 20 \beta$-pregnanediol from the milk, and showed that it competitively inhibited glucuronyl transferase (acceptor 0 -aminophenol) of guinea-pig liver.

We have now examined the effect of $3 \alpha, 20 \beta-$ pregnanediol on slices of human liver and solubilized human glucuronyl transferase, using bilirubin as the acceptor. We also tested other steroids that might be inhibitory.

\section{Materials and Methods}

The liver samples were from 2 adult men. One had a cerebral haemorrhage and the other glioblastoma multiforme. The specimens were obtained at the time kidneys were removed for transplantation. Previously the patients had been maintained by artificial respiration. The time during which the organs were subject to warm anoxia was between 20 and 30 minutes. The aerated samples were taken into Krebs-Ringer phosphate at $2^{\circ} \mathrm{C}$. and slices were prepared within $1 \frac{1}{2}$ hours. The period of anoxia was probably not important, as control experiments with rat liver slices showed that comparable anoxia did not remove the inhibition by pregnanolone.

For inhibitory studies with animals males were used.

Received 25 August 1969.
Rats (Wistar strain) weighed 200-300 g., rabbits (New $\overrightarrow{0}$ Zealand White strain) approximately $2 \mathrm{~kg}$., guinea-pigso 600-1000 g., and mice 25-30 g.

Bilirubin conjugation by liver slices was determinede from the amount of direct-reacting bilirubin in the incubation medium by the method of Lathe and Walker (1958a), with two modifications: a 5-minute 'direct'ô reaction time was used, instead of 30 minutes, and $0.2 \%$ $(\mathrm{w} / \mathrm{v})$ sodium azide, instead of ascorbic acid solution (B. H. Billing, 1969, personal communication), was used

Unconjugated steroids were obtained from $\mathrm{Koch}_{-} \frac{5}{5}$ Light Laboratories Ltd., or the Sigma Chemical Co Ltd. Sodium pregnanediol glucuronide was providedfrom the MRC Steroid Reference Collection by Professor W. Klyne. Bilirubin was obtained from British Druge Houses Ltd.

Solubilized glucuronyl transferase was prepared. according to the method of Halac and Reff (1967), witho omission of the EDTA step, and tested in the presence of $0.25 \mathrm{mM}$ UDPGA (Lathe and Walker, 1958a).

\section{Results}

The rates of bilirubin conjugation by human livern slices and solubilized glucuronyl transferase are given in Table I. The effects of adding a number of steroids are given. The results are comparedw with those obtained using liver slices from four? other species in Table II.

\section{Discussion}

Our results (Tables I and II) confirm the findings of Holton and Lathe (1963) that neither $3 \alpha, 20 \alpha-\frac{\pi}{\infty}$ pregnanediol nor its glucuronide inhibit bilirubin 
TABLE I

Effect of Pregnanediol Isomers, Oestriol, and Dehydroepiandrosterone on Bilirubin Conjugation by Slices and Solubilized Microsomes of Human Liver $\star$

\begin{tabular}{|c|c|c|c|}
\hline \multirow{3}{*}{ Addition } & \multicolumn{3}{|c|}{$\begin{array}{c}\text { Rate of Bilirubin Conjugation } \\
(\mu \mathrm{g} . / \mathrm{g} . \text { liver per } \mathrm{hr} .)\end{array}$} \\
\hline & \multirow{2}{*}{$\begin{array}{l}\text { Sample } 1 \\
\text { Slices }\end{array}$} & \multicolumn{2}{|c|}{ Sample 2} \\
\hline & & Slices & $\begin{array}{l}\text { Solubilized } \\
\text { Microsomes }\end{array}$ \\
\hline $\begin{array}{l}\text { None } \\
3 \alpha, 20 \alpha \text {-pregnanediol } \\
3 \alpha, 20 \beta \text {-pregnanediol } \\
\text { Oestriol } \\
\text { Dehydroepiandro- } \\
\quad \text { sterone }\end{array}$ & $\begin{array}{l}25 \cdot 5 \pm 3 \cdot 4 \\
28 \cdot 2 \pm 0 \cdot 8 \\
23 \cdot 3 \pm 3 \cdot 3 \\
12 \cdot 8 \pm 1 \cdot 7 \dagger \\
28 \cdot 8 \pm 0 \cdot 9\end{array}$ & $\begin{array}{l}21 \cdot 4 \pm 2 \cdot 7 \\
23 \cdot 7 \pm 1 \cdot 7 \\
22 \cdot 4 \pm 2 \cdot 9 \\
12 \cdot 2 \pm 2 \cdot 0+ \\
21 \cdot 6 \pm 4 \cdot 2\end{array}$ & $\begin{array}{l}95 \pm 10 \\
99 \\
99 \\
91 \\
91\end{array}$ \\
\hline
\end{tabular}

*Steroids were added to a final concentration of $2.5 \times 10^{-4} \mathrm{M}$. Values determined in quadruplicate are given as the mean $\pm S D$. Values determined in duplicate are given as the mean. A dagger indicates that the rate is significantly $(\mathrm{p}<0.05$ according to Student's test) different from the rate in the absence of steroid.

conjugation by human liver slices. They also show that $3 \alpha, 20 \beta$-diol has no effect on slices, or solubilized glucuronyl transferase, from human liver.

It is difficult to accommodate these findings to the commonly held view that breast milk jaundice is caused by the inhibition of bilirubin conjugation in the infant liver, as a result of $3 \alpha, 20 \beta$-pregnanediol in the breast milk. This general concept has developed from the following five observations, each of which should be considered individually, as one or more of them may be incorrect. (In the following discussion the milk of mothers whose infants are considered to have breast milk jaundice is referred to as 'icterogenic' milk.)

(1) Icterogenic milk produces breast milk jaundice. The association of jaundice with breast milk feeding has been noted by several groups (Newman and Gross, 1963; Arias et al., 1964; Stiehm and Ryan, 1965; Arthur, Bevan, and Holton, 1966) on the basis of studies of individual babies. Arthur et al. (1966) also reported a larger number of infants with high serum bilirubin among those fed human milk than those on cow's milk. A causal relation between human milk feeding and jaundice was inferred from the more rapid clearance of jaundice when infants were taken off breast milk (Newman and Gross, 1963; Arias et al., 1964) and in 4 cases serum bilirubin rose again, or ceased to fall when an infant was returned to the breast (Arias et al., 1964; Stiehm and Ryan, 1965). There is thus no dispute about the clinical phenomenon.

(2) Icterogenic milk inhibits conjugation of bilirubin by human liver in vitro. Arias et al. (1964) first reported the inhibitory effect of icterogenic (but not control) milk on human (rat, rabbit, and guinea-pig) liver slices and homogenates, using bilirubin and 0 -aminophenol as substrates for conjugation. Arthur et al. (1966) confirmed that icterogenic milk inhibited bilirubin conjugation by rat liver slices. Ramos, Silverberg, and Stern (1966) reported that some milks were highly inhibitory (species, substrate, and tissue preparation were not stated).

(3) Icterogenic milk contains $3 \alpha, 20 \beta-$ pregnanediol. This has been reported only by Arias et al. (1964). Ramos et al. (1966) could find neither pregnanediol isomer, though it was not clear that the milk they examined was 'icterogenic' nor how it was studied.

(4) Oral administration of $3 \alpha, 20 \beta$-pregnane-

TABLE II

Percentage Inhibition by Steroids of Bilirubin Conjugation by Liver Slices from Different Species

\begin{tabular}{|c|c|c|c|c|c|c|}
\hline \multirow{2}{*}{ Steroid } & \multirow{2}{*}{ Concentration (M) } & \multicolumn{5}{|c|}{ Inhibition (\%) } \\
\hline & & Rat & Mouse & Rabbit & Guinea-pig & Human \\
\hline Oestriol & $\begin{array}{l}5 \cdot 0 \times 10^{-5} \\
2 \cdot 5 \times 10^{-4} \\
5 \cdot 0 \times 10^{-4}\end{array}$ & $\begin{array}{r}8(1) \\
21(1) \\
38(1)\end{array}$ & $\overline{50}(6)$ & $\frac{31}{51}(1)$ & $\begin{array}{l}\overline{49}(1) \\
41(1)\end{array}$ & $\begin{array}{l}30(1) \\
46(2) \\
-\end{array}$ \\
\hline Pregnanolone & $\begin{array}{l}2.5 \times 10^{-5} \\
2.5 \times 10^{-4} \\
5.0 \times 10^{-4}\end{array}$ & $\begin{array}{l}50(6) \\
-\end{array}$ & $\underline{6}(6)$ & $\frac{4}{34}(1)$ & $\frac{6}{24}_{(1)}^{(1)}$ & $\overline{26}(2)$ \\
\hline $3 \alpha, 20 \beta-P r e g n a n e d i o l ~ g l u c u r o n i d e$ & $1.0 \times 10^{-6}$ & $41+$ & $31(6)$ & $2(2)$ & $-7(2)$ & $-2(2)$ \\
\hline
\end{tabular}

^Each value (based on quadruplicate determinations) is the mean of the inhibitions determined on the number of individual animals indicated in parentheses. Different animals were used when oestriol and pregnanolone were tested at different concentrations. The dagger indicates a result calculated from Bevan, Holton, and Lathe (1965). 
diol produces a rise in serum bilirubin in newborn infants. Arias and Gartner (1964) noted this in 2 of 4 infants who were given 0.33 mg./kg. per day. 2 larger infants did not respond. Ramos et al. (1966) gave $1 \mathrm{mg}$./day of the $20 \beta$-diol to 16 newborn infants, and $1 \mathrm{mg}$./day of the $20 a-$ diol to 4 infants, without effect. Lauritzen and Lehmann (1967) administered 3a,20 $\alpha$-pregnanediol (10 mg./day, intramuscularly) to 2 5-day-old infants and reported a subsequent increase in the serum bilirubin concentration. Oestriol and cortisone administration had the same effect.

(5) $3 \alpha, 20 \beta$-pregnanediol inhibits bilirubin glucuronide formation by liver preparations. Both $20 \alpha$ and $20 \beta$-diols were tested by Lathe and Walker (1958b) at a concentration of about $10^{-5} \mathrm{M}$. They noted marked species differences, exemplified by strong inhibition of rat liver slices but not of slices of Macaca mulatta liver. Holton and Lathe (1963) showed that human liver slices did not respond to $3 \alpha, 20 \beta$-pregnanediol (or its glucuronide). Though Arias et al. (1964) tested the effect of icterogenic milk on human liver slices with bilirubin as a substrate, $3 a, 20 \beta$-pregnanediol was examined with guinea-pig microsomes using $o$-aminophenol as a glucuronyl acceptor. Our studies have now shown that bilirubin conjugation by slices from 2 human livers (and soluble enzyme from 1) was not inhibited by $3 a, 20 \beta$-pregnanediol, even at high concentrations (Table I). Moreover, the amounts of the $20 \beta$-diol which were said to occur in icterogenic milk would be too little to inhibit the most sensitive test system-rat liver slices using bilirubin. Arias et al. (1964) estimated that about $1 \mathrm{mg}$. of the $20 \beta$-diol was secreted in the milk per day. Assuming that $500 \mathrm{ml}$. milk were produced, and taking account of the 12-fold dilution in Arias' in vitro system, the final steroid concentration would be less than $10^{-6} \mathrm{M}$. This is insufficient to produce $51-66 \%$ inhibition of rat liver slices by icterogenic milk which Arias et al. (1964) reported.

In summary, though there is general agreement about the first 2 observations, the latter 3 are not consistently supported. Part of the conflicting evidence regarding the latter 3 observations might be explained if breast milk jaundice were an expression of inherited biochemical defect. This would require the additional assumption that the biochemical defect, shown in the mothers by the secretion of $20 \beta$-diol in the milk, was expressed in their infants with the same trait by sensitivity to, or inability to metabolize, this steroid. If true, this could only be detected by tests on the liver of the affected infants, which would explain the negative results of administering $20 \beta$-diol in vivo. (Ramos et al., 1966) and in vitro (Table I). How- $\vec{F}$. ever, this hypothesis would require that the two ${ }^{\text {क }}$ infants (Arias and Gartner, 1964) who responded toc $20 \beta$-diol were, by chance, individuals with this trait $\overline{\bar{\varphi}}$. The infrequency of breast milk jaundice (even allowing for the unpopularity of breast feeding) $?$ makes this possibility remote. It seems much mores probable that the in vitro inhibitor of icterogenic milk is not $3 a, 20 \beta$-pregnanediol, and remains to be identified by further work.

If a further search is to be made for inhibitors ing breast milk it is important that this should be doneू with a test system which responds similarly tos human liver. Rat liver is very sensitive to pregnanediol glucuronide (Bevan et al., 1965) to pregnanolone (Adlard, Lester, and Lathe; 1969), and to other $5 \beta$-pregnane and androstanes derivatives, which may affect primarily secretion of conjugated bilirubin rather than its conjugation. This is indicated by the accumulation of conju $\rightarrow$ gated pigments in the rat liver slice. In contrast? pregnanolone produced a relatively small inhibition of rabbit, guinea-pig, and human liver and thend only at 10-20 times the concentration causing $50 \%$ inhibition in the rat. These three species did not respond to pregnanediol glucuronide. All fives species were inhibited by oestriol. Our studie. suggest that the rabbit or guinea-pig would be more appropriate for a study of icterogenic mille than the rat or mouse.

We thank the Medical Research Council for support? REFERENCES

Adlard, B. P. F., Lester, R. G., and Lathe, G. H. (1969). Thळ్ effect of phenobarbitone treatment of rats and of proteiri deprivation on the capacity of liver slices to conjugate bilirubin $\bar{S}$ Biochemical Pharmacology, 18, 59.

Arias, I. M., and Gartner, L. M. (1964). Production of unconjūं gated hyperbilirubinaemia in full-term new-born infant@ following administration of pregnane-3 $\alpha, 20 \beta$-diol. Natureె (London), 203, 1292.

$\longrightarrow$ - - Seifter, S., and Furman, M. (1964). Prolonged neonatal unconjugated hyperbilirubinemia associated with breast feeding and a steroid, pregnane-3 $\alpha, 20 \beta$-diol in maternat milk that inhibits glucuronide formation in vitro. fournal c玉. Clinical Investigation, 43, 2037.

Arthur, L. J. H., Bevan, B. R., and Holton, J. B. (1966). Neonata( hyperbilirubinaemia and breast feeding. Developmental Medi cine and Child Neurology, 8, 279.

Bevan, B. R., Holton, J. B., and Lathe, G. H. (1965). The effect of pregnanediol and pregnanediol glucuronide on bilirubin conjugation by rat liver slices. Clinical Science, 29, 353.

Halac, E., Jr., and Reff, A. (1967). Studies on bilirubin UDRO glucuronyltransferase. Biochimica et Biophysica Acta, 1395

328.
Holton, J. B., and Lathe, G. H. (1963). Inhibitors of bilirubin conjugation in new-born infants' serum and male urine. Clinicatb Science, 25, 499.

Lathe, G. H., and Walker, M. (1958a). The synthesis of bilirubio glucuronide in animal and human liver. Biochemical fournatด 70, 705. 
- and - (1958b). Inhibition of bilirubin conjugation in rat liver slices by human pregnancy and neonatal serum and steroids. Quarterly fournal of Experimental Physiology and Cognate Medical Sciences, 43, 257.

Lauritzen, C., and Lehmann, W. D. (1967). The significance of steroid hormones for the development of hyperbilirubinaemia and icterus in the newborn infant. Fournal of Endocrinology, 39, 183.

Newman, A. J., and Gross, S. (1963). Hyperbilirubinemia in breast-fed infants. Pediatrics, 32, 995.

Ramos, A., Silverberg, M., and Stern, L. (1966). Pregnanediols and neonatal hyperbilirubinemia. American fournal of Diseases of Children, 111, 353.

Stiehm, E. R., and Ryan, J. (1965). Breast-milk jaundice. American fournal of Diseases of Children, 109, 212.

\section{Addendum}

Further reports of clinical observations have been reviewed by Schneegans et al. (1969). Krauer-Mayer, Keller, and Hottinger (1968) reported 5 cases. The icterogenic milk contained 20-42 $\mu$ g. 20 $\beta$-pregnanediol/ $100 \mathrm{ml}$. milk. Four control samples had none. Severi et al. (1969) examined the breast milk being taken by 7 patients with prolonged neonatal hyperbilirubinaemia. In $5,20-45 \mu \mathrm{g}$. $20 \beta$-pregnanediol $/ 100 \mathrm{ml}$. were found
(F. Severi, 1969, personal communication). These concentrations are less than one-fifth of those reported by Arias et al. (1964).

\section{REFERENCES}

Arias, I. M., Gartner, L. M., Seifter, S., and Furman, M. (1964). Prolonged neonatal unconjugated hyperbilirubinemia associated with breast feeding and a steroid, pregnane-3 $\alpha, 20 \beta$-diol, in maternal milk that inhibits glucuronide formation in vitro. fournal of Clinical Investigation, 43, 2037.

Krauer-Mayer, B., Keller, M., and Hottinger, A. (1968). Úber den frauenmilchinduzierten Icterus prolongatus des Neugeborenen. Helvetica Paediatrica Acta, 23, 68.

Schneegans, E., Rohmer, A., de Muralt, G., Heumann, G., Haarscher, A., Cohen, A., and Cronmuller, G. (1969). Alimentation du prématuré, p. 255. Expansion Scientifique Française, Paris.

Severi, F., Rondini, G., Zaverio, S., and Bruschelli, M. (1969). Prolonged neonatal hyperbilirubinaemia and pregnane- $3 \alpha, 20 \beta-$ diol in maternal milk. In Abstracts of the European Society for Paediatric Research and the European Society for Paediatric Gastroenterology, p. 28 . Karger, Basel.

Correspondence to Professor G. H. Lathe, Department of Chemical Pathology, School of Medicine, Leeds LS2 9NL. 